\title{
Cationic Grafting from Carbon Black VI. Grafting of Poly- etheresters from Carbon Black by Cationic Ring-Opening Terpolymerization of Tetrahydrofuran-Cyclic Acid Anhydrides-Epichlorohydrin
}

\author{
Norio TsuboKawa, Yu Jian, and Yasuo SONE \\ Department of Applied Chemistry, Faculty of Engineering, \\ Niigata University, \\ Ikarashi 2-8050, Niigata 950-21, Japan
}

(Received June 27, 1986)

\begin{abstract}
The cationic ring-opening terpolymerization of tetrahydrofuran (THF)-phthalic anhydride (PAn)-epichlorohydrin (ECH) was found to be initiated by carbon black having $\mathrm{CO}^{+} \mathrm{ClO}_{4}{ }^{-}$groups. The activation energy of the terpolymerization was estimated to be 13.8 $\mathrm{kcal} \mathrm{mol}^{-1}$. Evidence for the formation of random terpolymers was obtained by IR, NMR, and GPC analysis. The composition of terpolymer was affected by an initial monomer charge ratio: the content of PAn in terpolymer decreased and that of ECH increased with an increase in the amount of ECH charged. Terpolymer of a 1:1:1 ratio could be prepared when THF, PAn, and ECH were charged in mole ratios of $1: 1: 0.7$. In such a polymerization system, terpolymer formed is effectively grafted from carbon black surface depending upon the propagation of polymer chain from $\mathrm{CO}^{+} \mathrm{ClO}_{4}{ }^{-}$groups. The grafting ratio and molecular weight of ungrafted polymer were found to decrease with a rise in polymerization temperature. Furthermore, the dispersibility of terpolymergrafted carbon black in chloroform was investigated.
\end{abstract}

KEY WORDS Ring-Opening Terpolymerization / Random Terpolymer / Polyetherester / Tetrahydrofuran / Phthalic Anhydride / Epichlorohydrin / Grafting / Carbon Black / Acylium Perchlorate Group on Carbon Black / Dispersibility /

In order to prepare carbon black which can be dispersed easily in various polymers, modification of the surface by grafting of polymers onto carbon black has been widely investigated. ${ }^{1}$ In a series of our papers, we reported the use of carbon black containing $\mathrm{CO}^{+} \mathrm{ClO}_{4}^{-}$groups, which are introduced by the reaction of $\mathrm{COCl}$ groups with $\mathrm{AgClO}_{4}$, for cationic grafting of polystyrene from carbon black. $^{2}$ Furthermore, it was described that $\mathrm{CO}^{+} \mathrm{ClO}_{4}^{-}$groups on carbon black have ability to initiate cationic ring-opening polymerization of lactones, ${ }^{3}$ cyclic ethers, ${ }^{4}$ and cyclic formals $^{5}$ to give polyester-, polyether-, and polyacetal-grafted carbon black, respectively.
On the other hand, polyetherester could be grafted onto carbon black during the cationic ring-opening isomerization polymerization of spiro ortho ethers initiated by carboxyl groups or $\mathrm{CO}^{+} \mathrm{ClO}_{4}^{-}$groups on carbon black. ${ }^{6}$

Hsieh has reported that alternating ringopening terpolymerization of cyclic ethers with cyclic acid anhydride is initiated by organometallic compounds, particularly trialkyl aluminum and the product has repeating ether-ester-ether linkages along the chain. ${ }^{7}$

In a previous paper, we reported that $\mathrm{CO}^{+} \mathrm{ClO}_{4}^{-}$groups have ability to initiate the cationic ring-opening copolymerization of tetrahydrofuran (THF) with cyclic acid an- 


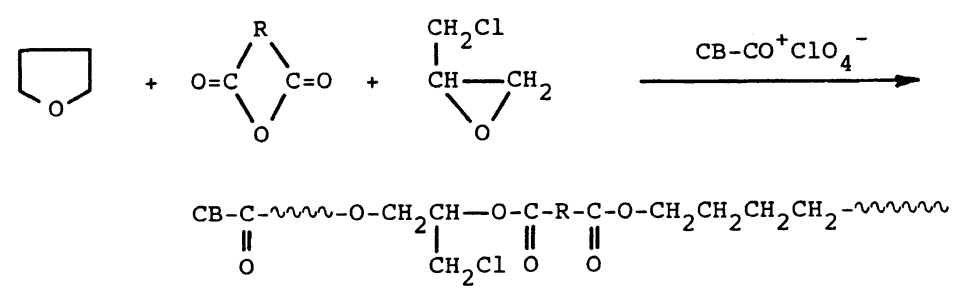

hydrides to give polyester-grafted carbon black. ${ }^{8}$ Moreover, it became apparent that by the addition of epichlorohydrin $(\mathrm{ECH})$ as a promoter, $\mathrm{ECH}$ sequences are included in the copolymer and the grafting ratio onto carbon black increased.

In the present paper, the grafting of polyetheresters by the ring-opening terpolymerization of THF-cyclic acid anhydride-ECH initiated by $\mathrm{CO}^{+} \mathrm{ClO}_{4}^{-}$groups on carbon black was investigated in order to graft polymers having reactive $\mathrm{CH}_{2} \mathrm{Cl}$ groups onto carbon black and to prepare polymer-grafted carbon black with a higher grafting ratio. Furthermore, the dispersibility of the terpolymergrafted carbon black was compared with that of several polymer-grafted carbon blacks.

\section{EXPERIMENTAL}

\section{Materials}

The carbon black used was color channel black Neospectra II (Columbian Carbon Co., BET specific surface area, $906 \mathrm{~m}^{2} \mathrm{~g}^{-1}$ ) and dried in vacuo at $110^{\circ} \mathrm{C}$ before use. The content of carboxyl, phenolic hydroxyl, and quinonic oxygen groups on the surface was $0.40,0.24$, and 0.92 meq $^{-1}$, respectively.

Tetrahydrofuran (THF) and epichlorohydrin $(\mathrm{ECH})$ were refluxed over calcium hydride and distilled twice before use. Phthalic anhydride (PAn), succinic anhydride (SAn), and maleic anhydride (MAn) were recrystallized and then sublimed under reduced pressure.
Nitrobenzene used as solvent was washed with dilute $\mathrm{H}_{2} \mathrm{SO}_{4}$, dried over $\mathrm{CaCl}_{2}$, and distilled under reduced pressure.

Guaranteed-reagent-grade $\mathrm{AgClO}_{4}$ (Kojima Chemical Co., Ltd., Japan) was dried in vacuo at $130^{\circ} \mathrm{C}$ before use. Boron trifluoride etherate and tin(IV) chloride were used without further purification.

\section{Introduction of $\mathrm{CO}^{+} \mathrm{ClO}_{4}^{-}$Groups onto $\mathrm{Car}$ - bon Black}

The introduction of $\mathrm{CO}^{+} \mathrm{ClO}_{4}^{-}$groups onto carbon black, i.e., pretreatment, was carried out by the reaction of $\mathrm{COCl}$ groups on carbon black with $\mathrm{AgClO}_{4}$ in nitrobenzene according to the method previously reported. ${ }^{2}$

The content of $\mathrm{CO}^{+} \mathrm{ClO}_{4}^{-}$groups introduced onto the carbon black surface was estimated to be 0.37 meq $^{-1}$ by the determination of $\mathrm{HClO}_{4}$ liberated after hydrolysis of CB$\mathrm{CO}^{+} \mathrm{ClO}_{4}^{-} \cdot$

\section{Polymerization Procedures}

After pretreatment, $10.0 \mathrm{mmol}$ of THF, $10 \mathrm{mmol}$ of cyclic acid anhydride, and $\mathrm{ECH}$ were added to a flask that contained $0.30 \mathrm{~g}$ of $\mathrm{CB}-\mathrm{CO}^{+} \mathrm{ClO}_{4}^{-}$and the polymerization was conducted with stirring under dry nitrogen. After the reaction, the product was poured into a large amount of methanol to precipitate the polymer and polymer-grafted carbon black. The precipitate was filtered, washed with methanol, and dried in vacuo. The conversion was calculated by the following equation:

$$
\text { Conversion }(\%)=\frac{\text { Precipitate obtained }(\mathrm{g})-\text { Carbon black used }(\mathrm{g})}{\text { Monomers used }(\mathrm{g})} \times 100
$$


Determination of Grafting Ratio and Intrinsic Viscosity of Ungrafted Polymer

To isolate polymer-grafted carbon black from the reaction product, the product was extracted with chloroform by using a Soxhlet apparatus until no more polymer could be extracted with the refluxing solvent. The grafting ratio was determined by the following equation:

$$
\begin{aligned}
& \text { Grafting ratio }(\%) \\
& \quad=\frac{\text { Polymer grafted }(\mathrm{g})}{\text { Carbon black used }(\mathrm{g})} \times 100
\end{aligned}
$$

On the other hand, the ungrafted polymer was isolated from the extract of the above extraction and purified by reprecipitation (chloroform/methanol). Its intrinsic visco- sity $([\eta])$ was determined with a Ubbelohde viscometer in chloroform solution at $30.0^{\circ} \mathrm{C}$.

\section{Dispersibility of Polymer-Grafted Carbon Black}

The dispersibility of polymer-grafted carbon black was estimated by the fraction of the carbon black dispersed in chloroform after centrifugation. Polyetherester-grafted carbon black $(0.50 \mathrm{~g})$ was dispersed in $50.0 \mathrm{ml}$ of chloroform with a magnetic stirrer and centrifuged at $5.0 \times 10^{3} \mathrm{rpm}$. After a definite time, $5.0 \mathrm{ml}$ of the dispersion liquid were taken out with a pipet and the amount of carbon black dispersed in chloroform was determined. The dispersing fraction was determined by the following equation:

$$
\text { Dispersibility }(\%)=\frac{\text { Carbon black dispersed after centrifugation }(\mathrm{g})}{\text { Carbon black dispersed before centrifugation }(\mathrm{g})} \times 100
$$

\section{RESULTS AND DISCUSSION}

Copolymerization of THF with $P A n$ in the Presence of ECH Initiated by $\mathrm{CB}-\mathrm{CO}^{+} \mathrm{ClO}_{4}^{-}$

Figure 1 shows the results of the copolymerization of THF with PAn initiated by CB$\mathrm{CO}^{+} \mathrm{ClO}_{4}^{-}$at $70^{\circ} \mathrm{C}$ in the presence of various amounts of $\mathrm{ECH}$.

From the results shown in Figure 1, the polymerization of THF was found to be initiated by $\mathrm{CB}-\mathrm{CO}^{+} \mathrm{ClO}_{4}^{-}$in the presence of PAn and $\mathrm{ECH}$. As mentioned in the previous paper, the rate of the polymerization was very small in the absence of ECH. However, by the addition of $\mathrm{ECH}$ the rate of polymerization and the conversion increased remarkably. These results clearly show that ECH acts as an effective promoter in the copolymerization of THF with PAn.

It is well known that in the polymerization of THF using ECH as a promoter, the ring-opening of $\mathrm{ECH}$ constitutes the initiation reaction, in which the propagating species (oxonium ion) is formed. ${ }^{10}$ It is considered that in the copolymerization of THF with PAn in the presence of $\mathrm{ECH}$, the ring-opening of $\mathrm{ECH}$ is also essential for the initiation

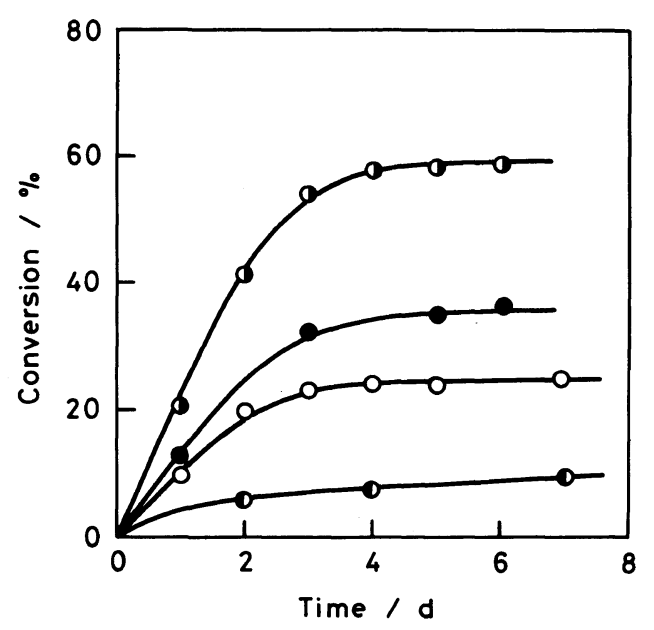

Figure 1. Copolymerization of THF with PAn initiated by $\mathrm{CB}-\mathrm{CO}^{+} \mathrm{ClO}_{4}{ }^{-}$in the presence of $\mathrm{ECH}$ at $70^{\circ} \mathrm{C}$. Pretreatment: Neospectra II-COCl, $0.30 \mathrm{~g}$; $\mathrm{AgClO}_{4}, 0.20 \mathrm{~g}$; nitrobenzene, $3.0 \mathrm{ml}$; room temp, $2 \mathrm{~h}$. Polymerization: $\mathrm{THF}=\mathrm{PAn}=10 \mathrm{mmol}, \quad \mathrm{ECH}=(\mathbf{O})$, $10 \mathrm{mmol}$; (O), $7 \mathrm{mmol}$; (O), $0.5 \mathrm{mmol}$; (O), $0 \mathrm{mmol}$. 
reaction. Therefore, the copolymerization of THF with PAn is accelerated by the addition of ECH.

It has been reported that the cationic ringopening terpolymerization of THF-ethylene oxide-PAn is initiated by organometallic compounds such as trialkylaluminum to give a polyetherester containing repeating etherester-ether linkage along the chain. ${ }^{7}$ On the other hand, Hilt and Hamann described that the copolymerization of THF with cyclic acid anhydrides is initiated by cationic catalyst such as $\mathrm{AlCl}_{3}$ and $\mathrm{SnCl}_{4}$ to give polyester. ${ }^{9}$

As mentioned above, we demonstrated that $\mathrm{CO}^{+} \mathrm{ClO}_{4}^{-}$groups introduced onto carbon black surface have ability to initiate the cationic polymerization of styrene ${ }^{2}$ and the cationic ring-opening polymerization of lactones, ${ }^{3}$ cyclic ethers, ${ }^{4}$ and cyclic formals. ${ }^{5}$

Based on these results, it is concluded that the cationic ring-opening copolymerization of THF with PAn in the presence of $\mathrm{ECH}$ is also initiated by $\mathrm{CO}^{+} \mathrm{ClO}_{4}^{-}$groups on carbon black. Moreover, the formation of terpolymer from THF, PAn, and ECH was expected when the copolymerization of THF and PAn is carried out in the presence of $\mathrm{ECH}$.

On the other hand, the rate of copolymerization decreased with an increase in the amount of ECH charged when it exceed 0.7 mmol. This may be due to the fact that the rate of propagation of $\mathrm{ECH}$ sequence, whose content in the polymer increases with an increase of $\mathrm{ECH}$ charged, is smaller than that of THF-PAn sequence. ${ }^{11}$ The effects of other promoters on the copolymerization of THF with PAn are now under investigation.

\section{Characterization of Ungrafted Polymer}

Figure 2 shows IR spectra of ungrafted polymers obtained from the copolymerization of THF with PAn in the absence or in the presence of $\mathrm{ECH}$, respectively.

Infrared spectra of the polymer obtained from the copolymerization of THF with PAn in the presence of $\mathrm{ECH}$ (charged in mole ratio,

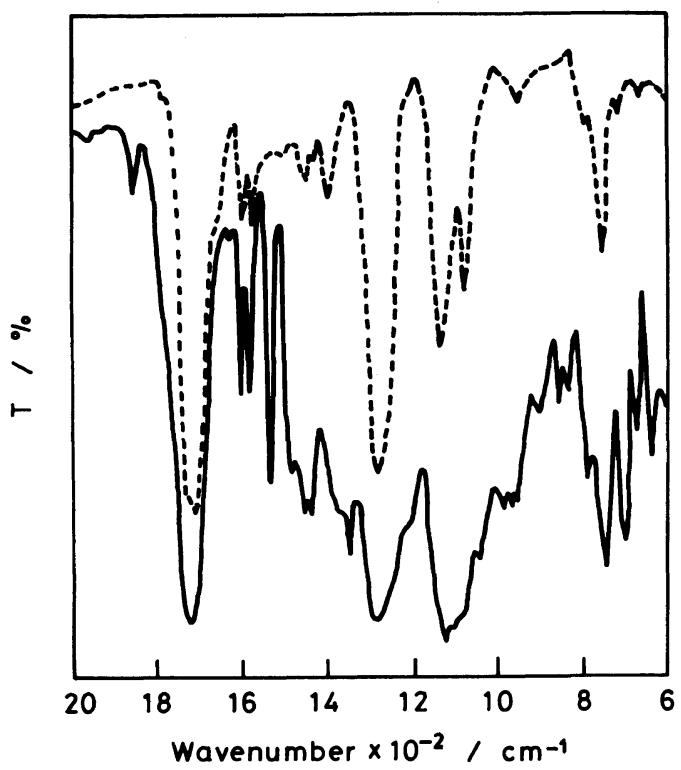

Figure 2. Infrared spectra of polymers obtained from the polymerization shown in Figure 1. Monomer charge ratio: (-), THF : PAn : $\mathrm{ECH}=1: 1: 0.7 ; \quad(----)$, THF $:$ PAn $=1: 1$.

THF:PAn:ECH $=1: 1: 0.7) \quad$ exhibited a strong absorption at $1118 \mathrm{~cm}^{-1}$ besides the one observed in the copolymer of THF and PAn. ${ }^{8}$ This absorption at $1118 \mathrm{~cm}^{-1}$ is characteristic of the ether bond, indicating the presence of an ether linkage in the polymer. The NMR spectra of the polymer suggest that the polymer contains $\mathrm{ECH}$ sequences: $\delta=$ $1.47-2.03\left(-\mathrm{CH}_{2}\right), 3.63-3.97 \quad\left(-\mathrm{CH}_{2} \mathrm{Cl}\right)$, $3.97-4.45\left(-\mathrm{CH}_{2} \mathrm{O}-\right), 4.43-4.77\left(-\mathrm{CH}_{2} \mathrm{O}-\right.$ $\mathrm{CO}-$ ), and $5.23-5.63 \mathrm{ppm}$ ( $>\mathrm{CH}-$ ).

These results indicate that the formation of terpolymer of THF-PAn-ECH, namely a polyetherester, as shown below. It was confirmed by NMR that the terpolymer from THF, PAn, and ECH charged in mole ratios of $1: 1: 0.7$ contains almost equimolar amounts of the three monomers.

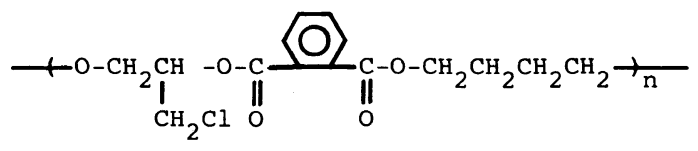




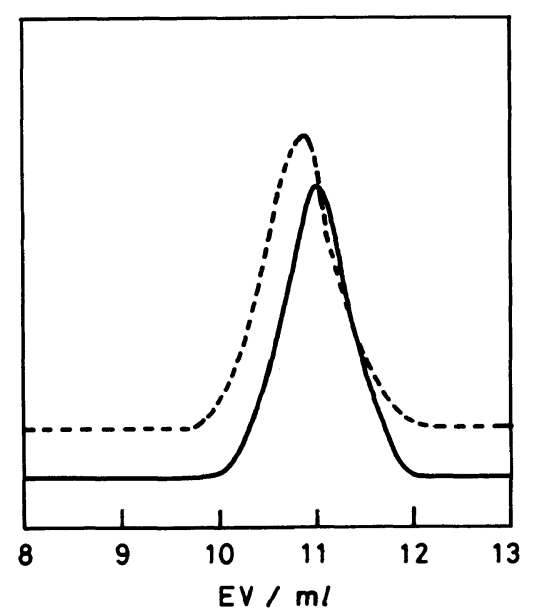

Figure 3. GPC curves of terpolymers obtained from the polymerization shown in Figure 1. Monomer charge ratio: (-), THF:PAn: $\mathrm{ECH}=1: 1: 0.7 ; \quad(---)$, THF : PAn : $E C H=1: 1: 1$. Measurement conditions: Column, GELPACK GLS300MDT5; solvent, DMF/ $\mathrm{THF}=1 / 1$; detector, differential refractometer; flow rate, $1 \mathrm{ml} / \mathrm{min}$.

From GPC analysis of the terpolymers (monomer charge ratio; THF: $\mathrm{PAn}: \mathrm{ECH}=$ $1: 1: 1$ and $1: 1: 0.7$ ), as shown in Figure 3, it is concluded that these polymers obtained in the presence of $\mathrm{ECH}$ are terpolymer from $\mathrm{THF}, \mathrm{PAn}$, and $\mathrm{ECH}$, but not a mixture of polyether and polyester. The molecular weight of these terpolymers was estimated to be 4.0 $-5.0 \times 10^{3}$ from GPC based on standard polystyrene.

Moreover, the polymer was fractionated into 3 fractions by fractional precipitations (chloroform/methanol). Difference in the composition of terpolymers of these fractions was scarcely observed by NMR and IR.

Based on the above results, it is concluded that when copolymerization of THF with PAn is conducted in $\mathrm{ECH}$, random terpolymer of THF-PAn-ECH is produced.

\section{Proof of Grafting from Carbon Black}

The carbon black obtained from the polymerization produced a stable colloidal dispersion in organic solvents such as THF and

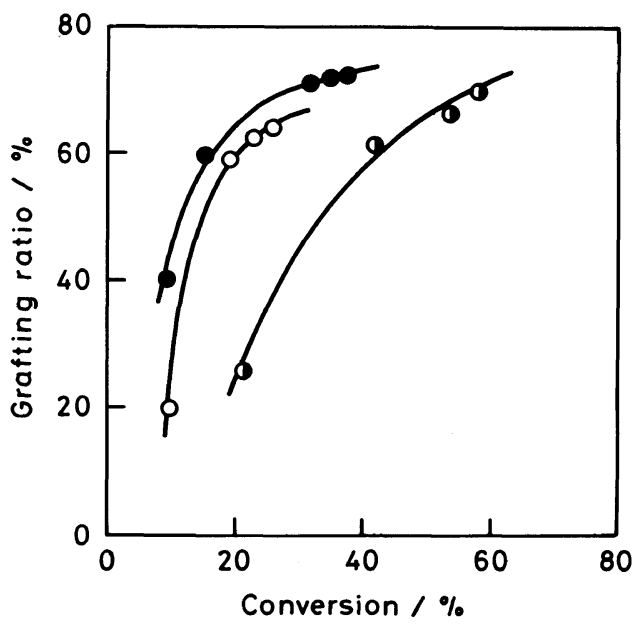

Figure 4. Relationship between conversion and grafting ratio of terpolymers onto carbon black. Polymerization conditions are given in Figure 1. Monomer charge ratio: (O), THF : PAn: $\mathrm{ECH}=1: 1: 1$; (О), THF $:$ PAn $: E C H=1: 1: 0.7$; (O), THF $:$ PAn $: E C H=$ $1: 1: 0.05$.

chloroform. This suggests that the terpolymer is grafted from the carbon black surface.

The relationship between the grafting ratio and conversion for each concentration of $\mathrm{ECH}$ charged is shown in Figure 4. Figure 4 shows that in such a terpolymerization system, the terpolymer formed is grafted from carbon black and the grafting ratio increases with an increase in conversion.

Accordingly, it became apparent that the terpolymerization of THF-PAn-ECH can be initiated by $\mathrm{CO}^{+} \mathrm{ClO}_{4}^{-}$groups on the carbon black surface and terpolymers formed are effectively grafted from carbon black based on the propagation of the polymer from the surface.

Effects of Charge Ratio of Monomers on the Terpolymerization

Using equimolecular amounts $(10 \mathrm{mmol})$ of THF and PAn and various amounts of $\mathrm{ECH}$, the terpolymerization of THF-PAn-ECH initiated by $\mathrm{CB}-\mathrm{CO}^{+} \mathrm{ClO}_{4}^{-}$was carried out at $70^{\circ} \mathrm{C}$. The results are summarized in Table $\mathrm{I}$.

The rate of the terpolymerization increased 
Table I. Terpolymerization of THF-PAn-ECH initiated by $\mathrm{CB}-\mathrm{CO}^{+} \mathrm{ClO}_{4}{ }^{-\mathrm{a}}$

\begin{tabular}{|c|c|c|c|c|c|c|c|c|}
\hline \multicolumn{3}{|c|}{ Monomer charge $/ \mathrm{mmol}$} & \multirow{2}{*}{$\frac{\text { Time }}{d}$} & \multirow{2}{*}{$\frac{\text { Conversion }}{\%}$} & \multirow{2}{*}{$\frac{\text { Grafting ratio }}{\%}$} & \multicolumn{3}{|c|}{ Mole ratio in polymer } \\
\hline $\mathrm{THF}$ & PAn & $\mathrm{ECH}$ & & & & THF & PAn & $\mathrm{ECH}$ \\
\hline 10 & 10 & 0 & 7 & 9.8 & - & 0.52 & 0.48 & 0 \\
\hline 10 & 10 & 1 & 6 & 54.5 & 70.4 & 0.42 & 0.45 & 0.13 \\
\hline 10 & 10 & 5 & 5 & 68.4 & 95.2 & 0.34 & 0.40 & 0.26 \\
\hline 10 & 10 & 7 & 5 & 57.3 & 69.8 & 0.33 & 0.34 & 0.33 \\
\hline 10 & 10 & 10 & 5 & 35.8 & 65.8 & 0.34 & 0.20 & 0.46 \\
\hline 10 & 10 & 20 & 5 & 12.7 & 57.6 & 0.39 & 0.08 & 0.53 \\
\hline 10 & 10 & 50 & 5 & 9.9 & 72.8 & 0.40 & 0 & 0.60 \\
\hline
\end{tabular}

a Pretreatment: Neospectra II-COCl, $0.30 \mathrm{~g} ; \mathrm{AgClO}_{4}, 0.20 \mathrm{~g}$; nitrobenzene, $3.0 \mathrm{ml}$; room temp, $2 \mathrm{~h}$. Polymerization, $70^{\circ} \mathrm{C}$.

with an increase in the amount of $\mathrm{ECH}$ charged until up to $5 \mathrm{mmol}$, but decreased when ECH was added more than $5 \mathrm{mmol}$. On the other hand, the mole ratios of PAn in the terpolymer decreased with an increase in the amount of ECH added. It was found that the terpolymer of a $1: 1: 1$ ratio can be prepared when THF, PAn, and ECH are charged in mole ratios of $1: 1: 0.7$. Then, when the polymerization was carried out in the presence of excess ECH (exceed $10 \mathrm{mmol}$ ), the structure of the polymer formed became close to that of the copolymer of THF with ECH.

Accordingly, it became apparent that polyetheresters with various compositions can be effectively grafted onto a carbon black surface by the terpolymerization of THF-PAn-ECH using $\mathrm{CB}-\mathrm{CO}^{+} \mathrm{ClO}_{4}^{-}$as initiator.

Initiation of Terpolymerization by Other Cationic Catalysts

Table II shows the result of the terpolymerization of THF-PAn-ECH initiated by benzoyl perchlorate, boron trifluoride etherate, and $\operatorname{tin}(\mathrm{IV})$ chloride at $70^{\circ} \mathrm{C}$. As shown in Table II, these catalysts have ability to initiate the terpolymerization of THF-PAn-ECH as well as $\mathrm{CB}-\mathrm{CO}^{+} \mathrm{ClO}_{4}^{-}$. Further investigations of the terpolymerization initiated by other cationic catalysts and the detailed characterization of the terpolymer are now in progress.
Table II. Terpolymerization of THF-PAn-ECH initiated by several cationic catalysts ${ }^{\mathrm{a}}$

\begin{tabular}{|c|c|c|c|c|c|}
\hline \multirow{2}{*}{ Catalyst } & \multirow{2}{*}{$\mathrm{mmol}$} & \multirow{2}{*}{$\frac{\text { Conversion }}{\%}$} & \multicolumn{3}{|c|}{$\begin{array}{c}\text { Mole ratio in } \\
\text { polymer }\end{array}$} \\
\hline & & & THF & PAn & $\mathrm{ECH}$ \\
\hline $\mathrm{Ph}-\mathrm{CO}^{+} \mathrm{ClO}_{4}^{-}$ & 1 & 35.8 & 0.30 & 0.23 & 0.47 \\
\hline $\mathrm{BF}_{3} \mathrm{OEt}_{2}$ & 1 & 40.5 & 0.37 & 0.35 & 0.28 \\
\hline $\mathrm{SnCl}_{4}$ & 2 & 38.5 & 0.22 & 0.33 & 0.45 \\
\hline
\end{tabular}

a $\mathrm{THF}=\mathrm{PAn}=\mathrm{ECH}=10 \mathrm{mmol}$; nitrobenzene, $3.0 \mathrm{ml}$; $70^{\circ} \mathrm{C} ; 5$ day.

Effects of Temperature on the Terpolymerization and Grafting Ratio of Terpolymer

Using $10 \mathrm{mmol}$ of THF, $10 \mathrm{mmol}$ of PAn, and $7 \mathrm{mmol}$ of $\mathrm{ECH}$, terpolymerization was carried out at 30,50 and $70^{\circ} \mathrm{C}$ and the effects of temperature on the terpolymerization and grafting ratio of terpolymer onto carbon black were examined. The results are show in Figures 5 and 6.

Figure 5 clearly shows that the rate of the terpolymerization at $30^{\circ} \mathrm{C}$ does not proceed more than $5 \%$ conversion even after 6 days. While at $70^{\circ} \mathrm{C}$, the terpolymerization was accelerated and $70 \%$ conversion was obtained after 6 days.

The activation energy of the polymerization was estimated to be $13.8 \mathrm{kcal} / \mathrm{mol}$. This value is somewhat larger than that of the ringopening polymerization of THF initiated by 


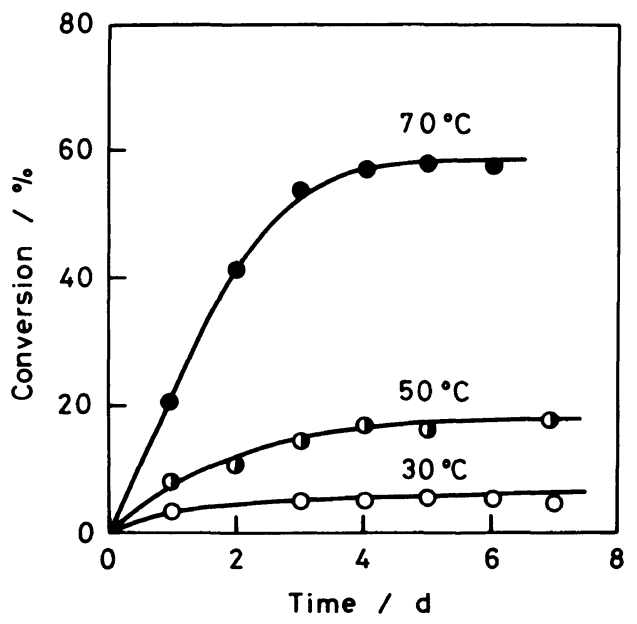

Figure 5. Effects of temperature on the terpolymerization of THF-PAn-ECH. Pretreatment: Neospectra II$\mathrm{COCl}, 0.30 \mathrm{~g} ; \mathrm{AgClO}_{4}, 0.20 \mathrm{~g} ;$ nitrobenzene, $3.0 \mathrm{ml}$; room temp, 2 h. Polymerization: $\mathrm{THF}=\mathrm{PAn}=10 \mathrm{mmol}$, $\mathrm{ECH}=7 \mathrm{mmol}$.

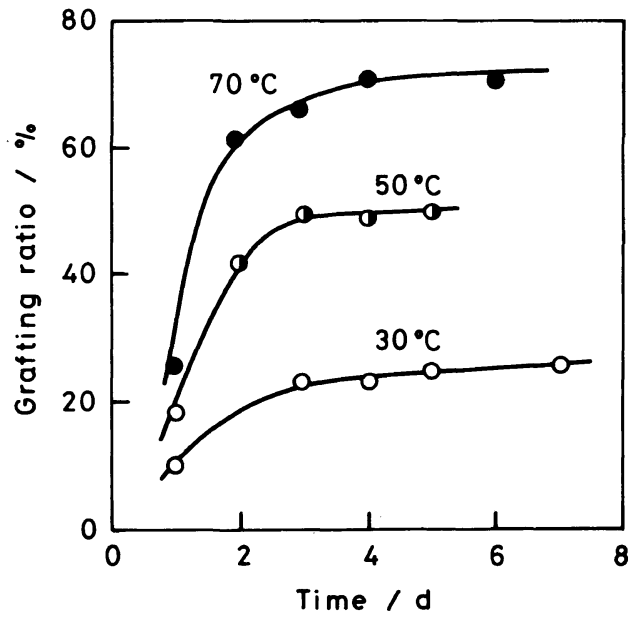

Figure 6. Effects of temperature on the grafting ratio of terpolymer from THF, PAn, and ECH. Polymerization conditions are given in Figure 5.

\section{$\mathrm{CB}-\mathrm{CO}^{+} \mathrm{ClO}_{4}^{-}$.}

The grafting ratio of the terpolymer increased with an increase in conversion at each temperature as shown in Figure 6.

The relationship between polymerization temperature and the intrinsic viscosity of ungrafted polymer is shown in Figure 7. The

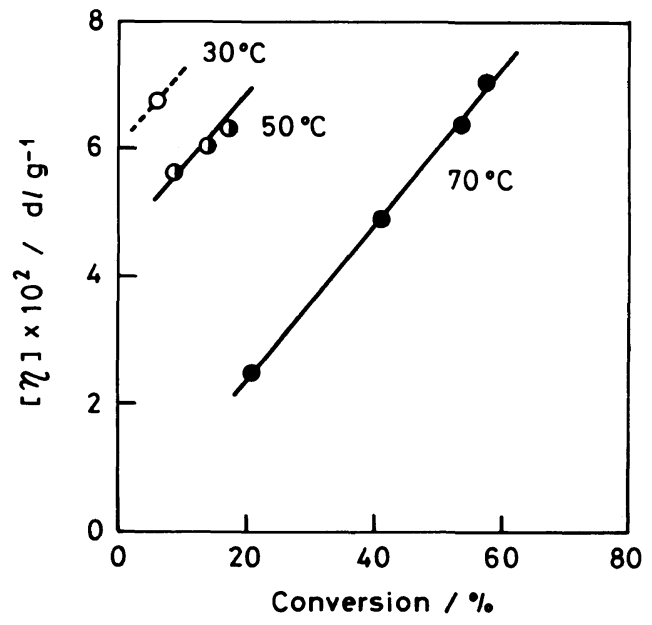

Figure 7. Effects of temperature on the intrinsic viscosity of ungrafted terpolymer from THF, PAn, and ECH. Polymerization conditions are given in Figure 5.

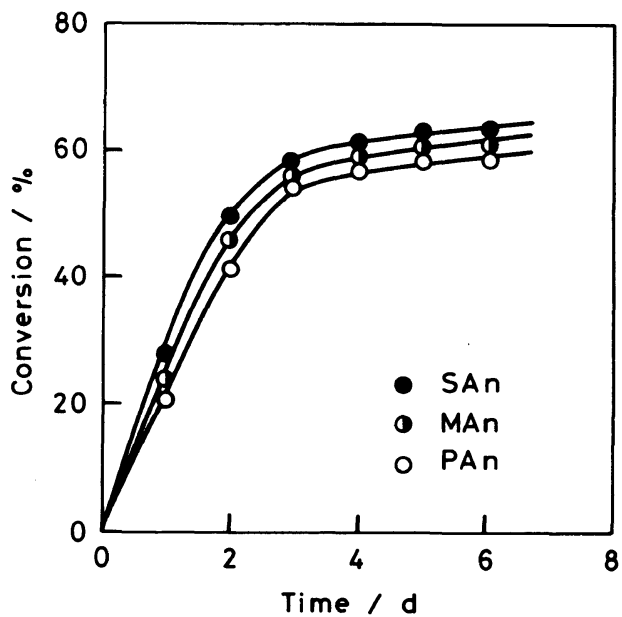

Figure 8. Terpolymerization of $\mathrm{THF}-$ cyclic acid anhydride-ECH initiated by $\mathrm{CB}-\mathrm{CO}^{+} \mathrm{ClO}_{4}{ }^{-}$. Pretreatment: Neospectra II, $0.30 \mathrm{~g} ; \mathrm{AgClO}_{4}, 0.20 \mathrm{~g}$; nitrobenzene, $3.0 \mathrm{ml}$; room temp, $2 \mathrm{~h}$. Polymerization: $\mathrm{THF}=$ anhydride $=10 \mathrm{mmol}, \mathrm{ECH}=7 \mathrm{mmol} ; 70^{\circ} \mathrm{C}$.

intrinsic viscosity of ungrafted terpolymer obtained at higher temperature was lower than that at lower temperature, possibly because the increasing temperature of the polymerization causes an increase in the rate of chain transfer of the growing polymer chains. 
Table III. Terpolymerization of THF-cyclic acid anhydride-ECH initiated by $\mathrm{CB}-\mathrm{CO}^{+} \mathrm{ClO}_{4}^{-{ }^{-a}}$

\begin{tabular}{|c|c|c|c|c|c|}
\hline \multirow{2}{*}{ Anhydride } & \multirow{2}{*}{$\frac{\text { Conversion }}{\%}$} & \multirow{2}{*}{$\frac{\text { Grafting ratio }}{\%}$} & \multicolumn{3}{|c|}{ Mole ratio in polymer } \\
\hline & & & THF & Anhydride & $\mathrm{ECH}$ \\
\hline PAn & 57.3 & 69.3 & 0.33 & 0.34 & 0.33 \\
\hline MAn & 58.2 & 84.1 & 0.28 & 0.37 & 0.34 \\
\hline SAn & 59.8 & 100.3 & 0.20 & 0.46 & 0.34 \\
\hline
\end{tabular}

a Pretreatment: Neospectra II-COCl, $0.30 \mathrm{~g} ; \mathrm{AgClO}_{4}, 0.20 \mathrm{~g}$; nitrobenzene, $3.0 \mathrm{ml}$; room temp, $2 \mathrm{~h}$. Polymerization: $\mathrm{THF}=$ anhydride $=10 \mathrm{mmol}, \mathrm{ECH}=0.7 \mathrm{mmol} ; 70^{\circ} \mathrm{C} ; 5$ day.

Table IV. Dispersibility of several polymer-grafted carbon black in chloroform

\begin{tabular}{|c|c|c|c|c|}
\hline \multirow{2}{*}{ Polymer grafted } & \multirow{2}{*}{$\frac{\text { Grafting ratio }}{\%}$} & \multicolumn{3}{|c|}{ Dispersibility $/ \%{ }^{a}$} \\
\hline & & $10 \mathrm{~min}$ & $1 \mathrm{~h}$ & $3 \mathrm{~h}$ \\
\hline Ungrafted & - & 0 & 0 & 0 \\
\hline Polystyrene $^{12}$ & 153.7 & 100 & 98 & 91 \\
\hline Poly $(\beta \text {-propiolactone })^{13}$ & 154.8 & 100 & 100 & 96 \\
\hline Polyester(THF-PAn) ${ }^{8}$ & 70.4 & 65 & 40 & 9 \\
\hline Polyetherester(THF-PAn-ECH) & 69.8 & 78 & 63 & 20 \\
\hline Polyetherester(THF-SAn-ECH) & 100.3 & 97 & 84 & 70 \\
\hline
\end{tabular}

a After centrifugation at $5.0 \times 10^{3} \mathrm{rpm}$ at room temperature.

Terpolymerization of THF-Cyclic Acid Anhydrides- $\mathrm{ECH}$ Initiated by $\mathrm{CB}-\mathrm{CO}^{+} \mathrm{ClO}_{4}^{-}$

The grafting of terpolymers onto carbon black was carried out with SAn or MAn as cyclic acid anhydride in place of PAn at $70^{\circ} \mathrm{C}$. The time-conversion curves of the polymerizations are shown in Figure 8.

As shown in Figure 8, the rate of the polymerization increased depending on the cyclic acid anhydride, in the following order: PAn $<$ MAn $<$ SAn. The grafting ratio onto carbon black and the composition of these terpolymers analyzed by NMR are summarized in Table III.

From these results, it was concluded that $\mathrm{CB}-\mathrm{CO}^{+} \mathrm{ClO}_{4}^{-}$has ability to initiate the cationic ring-opening terpolymerization of THF-cyclic acid anhydrides-ECH and that the polyetherester is effectively grafted onto the carbon black surface.

\section{Dispersibility of Terpolymer-Grafted Carbon} Black

As mentioned above, terpolymer-grafted carbon black produced a stable colloidal dispersion in chloroform. It is well known that the dispersibility of polymer-grafted carbon black is affected by its grafting ratio and solubility of grafted polymer chains in the dispersion medium. The dispersibility of a polyetherester (terpolymer of THF-PAnECH)- or polyester (copolymer of THFPAn)-grafted carbon black was compared with that of several polymer-grafted carbon blacks. The results are shown in Table IV.

Table IV clearly shows that the dispersibility of carbon black in chloroform is much improved by the grafting of polymers onto carbon black. The dispersibility of polymergrafted carbon black increases with an increase of its grafting ratio, because there is no difference in the solubility in chloroform between these polymers. Furthermore, it was 
found that the dispersibility of copolymer (THF-PAn)-grafted carbon black considerably improved by the introduction of $\mathrm{ECH}$ sequences in the grafted chain because of the increase of the grafting ratio. In particular, terpolymer (THF-SAn-ECH)-grafted carbon black with high grafting ratio produced a stable dispersion and its dispersibility was comparable to that of polystyrene- or poly$\beta$-propiolactone-grafted carbon black that obtained from anionic grafting. ${ }^{12,13}$

\section{REFERENCES}

1. N. Tsubokawa, Nippon Gomu Kyokaishi, 58, 306 (1985).

2. N. Tsubokawa, J. Polym. Sci., Polym. Chem. Ed., 22, 1515 (1984).

3. N. Tsubokawa, J. Appl. Polym. Sci., 30, 2041 (1985).
4. N. Tsubokawa, H. Nunokawa, and Y. Sone, J. Macromol. Sci.-Chem., A23, 105 (1986).

5. N. Tsubokawa, A. Yamada, and Y. Sone, Polym. Prepr., Jpn., 33, 256 (1984).

6. N. Tsubokawa, S. Ohshima, Y. Sone, and T. Endo, J. Polym. Sci., Polym. Chem. Ed., accepted for publication.

7. H. L. Hsieh, J. Macromol. Sci.-Chem., A7, 1525 (1973).

8. N. Tsubokawa, Yu Jian, A. Yamada, and Y. Sone, Polym. Bull., 16, 249 (1986).

9. A. Hilt, K. H. Reichert, and K. Hamann, Makromol. Chem., 101, 246 (1967).

10. T. Saegusa, H. Imai, and J. Furukawa, Makromol. Chem., 54, 218 (1962).

11. Y. Ishii and S. Sakai, "Ring-Opening Polymerization," K. C. Frisch and S. L. Reegen, Ed., Marcel Dekker Inc., New York, N.Y., 1966, p 16.

12. N. Tsubokawa, J. Makromol. Sci.-Chem., in press.

13. N. Tsubokawa, A. Funaki, Y. Hada, and Y. Sone, $J$. Polym. Sci., Polym. Chem. Ed., 20, 3297 (1982). 